\title{
Memory Anchored by Place Attachment and Cognitive Maps in Michael Ondaatje's Warlight and The Cat's Table
}

\author{
Justy Joseph ${ }^{1} \&$ Dr. Nirmala Menon ${ }^{2}$ \\ ${ }^{1} P h D$ Research Scholar, School of Humanities and Social Sciences, Indian Institute \\ of Technology Indore, India. ORCID id: 0000-0002-7182-0108. \\ Email id:phd19012610o6@iiti.ac.in \\ ${ }^{2}$ Associate Professor, School of Humanities and Social Sciences, Indian Institute of \\ Technology Indore. Email id: nmenon@iiti.ac.in
}

\begin{abstract}
Recollection is a gangplank between an obsolete past, indisputable present and an unidentified future, but human memory is convoluted as the compendium of a landscape. Perceptions, values and experiences fastened to a landscape can anchor memories, shift perceptions and can alter the aboriginal integrity and cognitive capabilities of an individual. This research article studies the Canadian Nobel Prize winning author Michael Ondaatje's novels The Cat's Table (2012) and Warlight (2018) venturing to understand how characters and their identities are created with the aid of memory. This study examines how place attachment and understanding of environmental configurations through generation of cognitive maps distorts or ascends recollection.
\end{abstract}

Keywords: place attachment, cognitive geography, cognitive maps, memory, landscape

\section{Introduction}

Reminiscence is a parlance between an obsolete past, irrefutable present and an anonymous future. "To remember is ... not simply to restore a forgotten link or moment of experience, nor is it unproblematically to repossess or re-enact what has been lost" (Nicholls 1996). It is to confide on the past to devise the present and future. An aboriginal integrity is restored in 'remembering the self, whereas re-remembering is a process of provisional reconstruction embedding the past and present selves together. Memory, the 'cornerstone of mind' is inherently geographic in all senses as it is a testament of past spaces and is wield in the present places. Each individual lives with the scars, sufferings and injustices of the past holding them in their memories and lingering them with the spaces which they once inherited. The activity of memory is founded in the fundamental distinction between past and present and a collective knowledge about history. Once the past is distinct, human beings endeavor to preserve, interpret, and appropriate their experiences. Literature throughout ages is a clairvoyant for unleashing memory process and its catalysis into artistic images. Remembering is conspicuous in literature, as artist Lily Briscoe in Virginia Woolf's To the Lighthouse, whose whole undertaking over years is to transmogrify her recollections of her friend Mrs. Ramsay into a painting.

\footnotetext{
(c) AesthetixMS 2020. This Open Access article is published under a Creative Commons Attribution Non-Commercial 4.0 International License (http://creativecommons.org/licenses/by-nc/4.o/), which permits non-commercial re-use, distribution, and reproduction in any medium, provided the original work is properly cited. For citation use the DOI. For commercial re-use, please contact editor@rupkatha.com.
} 
Michael Ondaatje, the best-known Booker prize winning Canadian novelist, employs the human thirst to somehow make sense of their past, throughout his 2012 novel The Cat's Table and 2018 novel Warlight. The Cat's Table, a perfect play between fiction and fact, is a story of a three-week travel of a eleven year old boy, from Colombo to London along with a ragtag group of "insignificant" adults and two other boys. What appeared to be the truth about the voyage for Michael, the protagonist, as an eleven-year-old boy takes on a very different meaning through his middle age experiences. Whereas in Warlight, a novel which is as deceptive and mysterious as memory itself, Ondaatje like a historian reveals the personal history of the protagonist Nathaniel, which is intertwined with the world history. The novel has the perils and prices of war as its central theme and the boundaries are constructed between ignorance and conception of identity, memory and distortion, childhood and adulthood and war and peace.

This paper attempts to study the effect of cognitive geography on human memory and memory retrieval analyzing of Michael Ondaatje's Warlight and The Cat's Table by Comprehending the role of 'place' and 'space' in the creation of memory and how place attachment distorts or ascends memory retrieval in the lives of the characters in the narratives. The study also focuses on the learning of environmental configurations through cognitive maps and its effects on memory encoding and retrieval of the characters. This study will extend the research on memory in literature and on the works of Michael Ondaatje by a theoretical and conceptual analysis on the efficaciousness of cognitive geography on human memory in the select novels.

\section{Place: A Clairvoyant of Memory}

Human memory is convoluted as the compendium of a landscape. Each person is a landscape engraved by memory and loss. An aggregate number of external factors can instigate the functioning of memory. Geography is one such factor which can affect the cognitive competency, memory encoding and recollection of an individual. Land cannot be muddled from the memory of its indweller. Nothing can designate an individual better than the factors influencing his dwelling. The exquisite, but authoritative amalgamation of place, human emotions and memory is complex, and it can never be amply comprehended. As Riley (1979) said in his paper "Reflections on the Landscape of Memory", the remembering of a place may have less to do with the place it is associated in firsthand, but more to do with the yearning for the feelings or emotions it once evoked.

Landscape is a place where we establish our own human organization of space and time. It is where the slow natural processes of growth and maturity and decay are deliberately set aside and history is substituted. A landscape is where we speed up or retard or divert the cosmic program and impose our own. (Cosgrove \& Jackson 1987)

The cultural inclinations of humanity have always made room for the sacredness of a landscape. All the spaces from a mountain hike to an antique empty room are inscribed with mankind's tenacious and ineluctable obsessions. Perceptions, values and experiences fastened to a landscape can anchor memories, shift perceptions gradually or dramatically and can create a historical identity. The place which we live is an embodiment of emotions; it becomes an aura of protection. Sense of place aids as pegs on which people hang memories, construct meaning, establish the notion of community and ratify the arenas of action. Attachment to a place replenishes the concept of identity and induces a sense of belongingness with flexibility and transcribes the experiences of a person. 


\section{Warlight : A Tale of Memories Recollected in the tranquility of Lost Spaces}

The novel Warlight by Michael Ondaatje dives into the lives of two teenagers, Nathaniel and Rachel and a group of unexpected characters who indelibly shape the lives of the teenagers by their unwitting involvement. The narrative is shadowed and luminous all at once as memory itself. Nathaniel understands his past at its best as a scattering of fragments and he is drawn into more shadowy worlds. His parting with his parents under the care of strangers, working during out-of'school hours, his consorts with Mr.Nkoma's elaborate story telling at workplace, working with Pimilico Darter on the river, finding a girlfriend with a name and nature as shadowy as the empty houses they habitually met, his mother's return to London, the absence of his father and the war time activities of his parents are all in the world of mists and mellow obscurity till he enters his childhood habitat that aids his recollection of the past .

Even though childhood is reckoned as the most sacred period of one's lifetime it is strenuous for the mind to perceive this abstract time period. Human brain tends to recreate this period of time by retrieving the memories bridging it with places inhabited.

We hold onto childhood memories of certain places as a kind of psychic anchor, reminding us of where we came from, of what we once were, or of how the environment nurtured us when family dynamics were strained. Whatever befalls us in later life, those memories remain; it is as though childhood is a temporal extension of the self. (Low \& Altman,1992)

Likewise, In the novel, Nathaniel in the safety and assurance of his childhood abode, in the loud noise of the wooden floor and in the tranquility of the walled garden with lilacs recollects his past and discovers the truth by gathering together the unconfirmed fragments from his childhood. The erased memories of a war time childhood and his parents' avocations during the war are recollected. Ondaatje writes: "I bought and moved into their small timbered house protected by that walled garden ... almost immediately a past that felt completely erased began returning" (127). Recollection and organization of memory by Nathaniel here follows a decree very much analogous to the unities of classical theater, which require unity of place, time and action.

Nathaniel's continuous intrigue his mother's identity remains hazy. In the anonymous and buried past of his mother he felt that he too has disappeared, and his youth is lost too. "Wars don't end," he says. "They never remain in the past". Rose's espionage works both during and after World War II and Marsh Felon, her shadowy acquaintance from childhood remains as a mystery for Nathaniel. Though Rose herself discloses that her "sins are various" (225), Nathaniel struggles to decipher the truth until at White Paint, in his mother's room, resting on her narrow sheet less bed, he remembers the story she told about the boy who lived on the roof of her family home. He 'steps into fragments of their story' and identifies Marsh felon, his mother's mysterious friend, a 'thatcher, naturalist, an authority on battle sites' and the one whom he met on the day of his mother's funeral. Nathaniel's recollection is intimately bound up in the relations he developed with his family and with the space around him through his actions and its intensity. Landscapes are abstractly 'spaces' or 'places' that reflexively subsist in his cognitive as well as corporeal experiences of the material world, which is being shaped by multiple identities. For him landscape is thus often characterized implicitly as a product of mindscape which is banded together with the realms of the cognitive and mnemonic consciousness. Memory can be about a forgotten past, reinforcing a lost identity and it can develop a sense of nostalgia to legitimize a lost heritage. Different versions of the past are communicated to an individual through landscapes and emotions underlying it and there is sometimes a struggle to create or subvert the past. The affective ties between people and place may vary in its intensity and expression but these bonds are primarily established as aesthetic and tactile, as Tuan writes in 
"Landscapes of Fear", 'More permanent and less easy to express are feelings that one has toward a place because it is home, the locus of memories, and the means of gaining a living' (Tuan 93).

Rose, mother of Nathaniel in Warlight displays an unanticipated attachment for the house she had inherited. Even though she had heralded her wish for disinheritance and exile, years back when she separated herself from her parents and later from her children, it was the old house at White Paint that she wanted to spend the rest of her life. She knew each slight incline of that house and memories of her childhood, her acquaintance with marsh felon and her entire biography were engraved on those walls. Rose, the most anonymous person throughout the novel displays a strange affinity towards spaces. As Wallace Stegner writes in Woolf Willow "I may not know who I am, but I know where I am from", Rose, though with a confused identity, is certain about the spaces which she belonged to. Nathaniel says:

She [Rose] ought to have choosen a different landscape, she said ... But it was an old house. She knew each slight incline of hall, every stiff window casing, the noise of winds during different seasons. She could have walked blind folded through its rooms into the garden ... It was her biography since her birth, her biology. I think it drove her mad. (253)

Rose repossesses enters her lost heritage and ancestral history being in her old inherited house. She enters into the lives of her grandmother and mother, waiting for their husbands to return from the war. She remembers herself preceded by all those women, in the same bedrooms, in the same twilight. That house reminds her of the prior life she ran away from and the same house was the inheritance she had come to. She was back to the family of thatcher's working on the roof, the postman and Mr. Malakite arriving with sketches of greenhouse he was building. The house opened the doors to her past and she was recreating her present in its eventual strangeness. Ondaatje writes:

She would open a door and find herself in her grandmother's life. She could witness the generations of women in their labours with a husband's visit now and then, and child after child, cry after cry, wood fire after wood fire, the banister smoothed from a hundred years of touch... She was once more back in a small repeating universe. (254)

The white house initiates a nostalgic and melancholic yearning for a forgotten past in Rose that in turn generate conscious strategies of memorializing. She intellectually conceptualizes a landscape built around the strategies of contestation and resistance. The process of remembering, identity and heritage creation through cultural landscapes here is neither autonomous nor uni-directional. Whereas It is complex and contradictory, as a place by itself is capable of generating contestation and conflict. Especially, as Rose belongs to a post-world war community she creates and celebrates landscapes as a resistance to the social and cultural processes.

Throughout the novel, Nathaniel's yearning to cast light on his family's secrets is allied with spaces which they once ingrained. His exalted aspiration to fudge together his own past identity is affirmed by the melancholic tang of the old house and the memories it aroused. Rose, who altercates her family ties is still found attached to her old inherited house and those antique rooms where her ligations to a forgotten past, an obscure history and a disdained self-identity is recollected. Nathaniel's mysterious lover is named as Agnes, because the street they habitually met was Agnes Street. Thus, characters in Warlight are found gravely attached to places they associate with and their memories are harbored at those spaces. The novel is constructed in a belief that places are lost inheritances. In a small hall of reflections of past and present spaces, everything is believed to rhyme and in those reflections the characters discover their missing pieces and things they have grown cautious and hesitant about, come almost casually to them. 


\section{The Cat's Table: a Recreation of Past Intertwining the Threads of Memory and Imagination Lured by Landscapes}

Memories effectuate the human desire to anchor their identity that exteriorizes itself in the quest for ancestors, family history and roots. It is precisely in this desire to trace the maze of relationships, Michael Ondaatje's novel The cat's table revisits the unforgettable three week voyage from Colombo to London that he (author) undertook in 1954. In this recollection the writer understands his childhood by mapping a space which he can identify as a home. Ondaatje, belonging to a Ceylonese family of Dutch-Tamil-Sinhalese origin was displaced to London at his age of eleven. The autobiographical recollection of this dislocation is a central aid in recreating the era of his parents that he knew mainly from stories he heard as a child (Running in the Family, 205). In accordance to the psychic reality and emotional resonance of the childhood impressions that the author recalls, identity of the characters as well as the author emerges and is reconstructed in the gap between the fictionalization and reality.

"Human difference is articulated in displacement, tangled cultural experiences, structures and possibilities of an increasingly connected but not homogenous world" (Clifford 1997). Dislocation is an attempt to outstrip the culture of the homeland and migrating to other cultures and imagined spaces. It results in the creation of a third space which can be understood in terms of trauma and conflict. The uncertainties in dislocation besiege slippages between inclusion and exclusion, alienation and belonging and placelessness and locatedness. The encroaching of history of homeland in third spaces, waves misplaced identities and lost individual selves. "Identity always presupposes a sense of location and a relationship with others and the representation of identity most often occur precisely at the point when there has been a displacement" (Bhabha 1995)

The Cat's table explores visceral reactions towards displacement. Bonds created during geographical mobility are contrasted with the longing for home. The voyage becomes a metaphor of the contingent and ephemeral diasporic experience of Michael, the protagonist named after the first name of the author. The ocean, the space to which Michael - nicknamed Mynah, always bound to becomes the microcosm of a later world, is portrayed as the ever conflicting dualities of self and other, inside and outside, familiar and strange, and center and periphery. In his coloured recollection stimulated by his attachment to ocean and a narration prompted in his middle age by his children, the sea voyage becomes affectively intense. "Identity always presupposes a sense of location and a relationship with others and the representation of identity most often occur precisely at the point when there has been a displacement" (Bhabha 1995). People who migrate are destined to flounder on some part of their life that is always elsewhere. Bewilderment in the immigrant country, remorse for the country of the past, and the yearning to rearticulate their identity actuates an emotional trauma. This trauma drives them back to their homeland even when they are in another space. Even when they venerate pluralized delicacies, they are stuck in a space which they really belonged to. Throughout the novel Michael the protagonist extorts a sense of loss an aggravating "wound" which, as Julia Kristeva writes, causes the exile to wander. Ondaatje confirms this unavoidable sense of displacement writing: "We all have an old knot in the heart we wish to loosen and untie" (145). Mynah was highly adhered to the grandeur of the world that he has left behind. The sights, smells, and sounds that surrounded him in the stern city of Aden are always contrasted with that in Colombo. The scattered unreliable inmates of the ship who became the essential and affectionate guides during the unformed stage of Michael's life made him question the world he supposedly belonged to. He longed for Colombo in every city he was in. He craved for throat catching odour of arong cloth and mangosteens in a sterner world with few luxuries. 
Michael tends to retain memories about certain places though they are relatively dangerous, and he develops a strange sort of affinity towards those spaces. Radically, he persuades and hooks himself in retaining those spaces without regarding the consequences. He after getting settled in London, chooses a dangerous summer abode which was frequently invaded by storms. The arrival of thunder and the danger of storms felt strangely assuaging and mitigating for Michael. He faced the storms as if within the velocity of some space travel experiment. Years after being in the hovering unsafe sea, during those stormy nights Mynah remembered that night on which he along with Cassius tethered themselves for what they thought to be an exciting adventure. The memory of the wild sea made him feel comfortable even during the wild storms in Canada, and the storms accelerates the recollection of his strange childhood.

Throughout the novel we find Michael attached to Colombo, Oronsay -the ship and the ocean. His extremely mobile childhood is punctuated by life experiences that are fragmented by each move and this movement affects his future life and identity formation. As Ondaatje writes: "There is a story, always ahead of you. Barely existing. Only gradually do you attach yourself to it and feel it. You discover the carapace that will contain and test your character. You find in this way the path of your life" (181). The anthropologist van Gennep coined the term 'rites of passage' to express the rites shared by individuals who have experienced international mobility as a child. He consequently named the tripartite pattern of passage as

- Separation (separated from the previous social statuses)

- Margin (in a neither here nor there state)

- Reaggregation (have a newly defined status and identity).

These rites of passage are clearly identifiable in Mynah and his attachment towards Colombo and then towards the Ocean. Undertaking an inner journey through the deeply submerged layers of memory Mynah chisels his present self. He arrives in the adventures of the present through "emotions recollected in tranquility" about the past. The novel celebrates the unrealized possibilities of the unique convalesce of past, present and future.

\section{Learning of Environmental Configurations through Cognitive Maps}

Extraneous representation of geographical information is often deficient, crude and misconstrued. Cognitive maps are mental representations of the external world converging on spatial relationships. They create an imaginal effigy of an individual's space of navigation with respect to his or her physical interactions. They seem to offer internal representations that simulate particular spatial features of the external environment. They aid in deflating the 'cognitive load' by visualizing and recalling the perceived information. Cognitive maps are one of the ways by which human mind tries to generate the mnemonic experience of historical continuity. The Brain views, encodes and understands landscapes to form identical and at times contrasting figures instead of just mnemonic pasting. They play a key role in understanding an individuals' spatial behavior and impinges on a vast array of behaviors.

\section{Comprehending Geographical Configurations through Cognitive Maps in Warlight}

cognitive map generating ability is evident in children beyond their age of seven. At about the age of seven, the child develops an objective spatial understanding and becomes able to structure the inter relatedness of his spatial environment. When trying to acquaint with familiar environment 
children tends to manipulate cognitive maps and their memory of space is perceptual in nature. A child understands the spatial structures of his daily environment in order to establish a comfort zone. This ability will be manifested in movement behavior, play or drawing and it evolves as he matures.

Nathaniel in the novel Warlight as a boy was obsessively drawing maps of his neighbourhood in order to feel secure. He often thought that what he could not see or record would cease to exist, just as he felt he had misplaced his mother and father in one of the small villages with no reliable mileage towards it. His childhood was spent in drawing maps that precisely radiated his environment and those maps were manifestations of his insecurity. Nathaniel has a well- developed understanding of familiar spaces and can represent them fairly accurately. He comprehends that all the elements in his space are parts of a whole and these elements are capable of retaining their identity despite transformation. He is capable of extrapolating routes within a general spatial structure and reverses mental operations based on the knowledge of his space.

Rose, got acquainted with Marsh Felon at her age of eight. Once she brought him a book from their family library and noticed a few sketches of flies for fishing in the last blank pages of it. The sketches, precise and legible unlike his handwriting seemed to be made by a different person. Later, the children constructed the fly, echoing the drawing. Felon, when he grew up engaged in climbing adventures during his college days, where he drew maze like illustrations and meticulous descriptions of best climbing routes. He sketched the "sparsely populated and largely anonymous buildings" (200) and prepared maps during the World War. Much of Felon's spatial cognition was through the construction of maps. He perceived, encoded and retrieved spatial information in the form of coherent and potent geographical illustrations.

The novel as it portrays world war scenes illustrates how construction and study of maps of geographical areas aided in keeping an eye on invasions. Rose and Felon are found engaged in creating detailed maps of places that belonged to their lists. Map was a tool of analysis and understanding of spaces. The spies of the war enter each street and as they leave they create a map of the street in their head. Nathaniel writes "She leaves the street of the small daggers and recovers the map in her head" (246).

Cartographic depictions of terrains assisted the development of long-range artillery during world wars. The characters Rose and Marsh Felon in the novel use their relatively high ability to perceive visual and spatial information to serve as spies during and after the war. Whereas for Nathaniel the transferring of acquired spatial information into maps was a contrivance to escape his insecurities. The novel acclaims the creation of cognitive maps as an effective functioning that recuperates the memory encoding and retrieval of spatial information.

\section{Comprehending Spatial Compositions through the Construction of Cognitive Maps in The Cat's Table}

Cognitive map knowledge is referred to as, an individual's perception about the established spatial and environmental affinities of a geographic space. This fundamental apprehension underlying spatial cognition arbitrates spatial behavior, choices, decision making and place attachment.

Michael, aka Myna is portrayed as a young boy "who goes out the door in the morning and will continue to be busy in evolving map off his world" (34) after his parents abandoned their marriage. Being displaced from Colombo to London, the ship voyage marked the transition in Mynah's life. The voyage transformed him into an able individual capable of perceiving the reality of visual 
stimuli he encodes. As a young boarder at St. Thomas College, Mount Lavinia, he loved anything to do with water and engaged in swimming in the flood waters in the concrete channels raced during the monsoons. His brain measured the height and depth of each current and this made him an efficient swimmer. He created a map of the pooled flood water, the grey rope, racing waters and the underground current. His attachment with ocean and the adventure it offers abetted him to perceive the stream of water explicitly.

The Cat's Table moves around Emily, Michael's 'machang' who lived almost his next door for years. She had a free spirit and wildness though she risked herself engaging in various adventures. Emily's record collection with all those lifetimes and desires rhymed together and distilled in two or three minutes of a song, brought Emily and Mynah closer. "Much of the time her father was away at job, or he simply disappeared. There was no secure map Emily could rely on, so she invented maps herself" (14). Emily, who is fond of adventures and discovering places, is creating illustrations of places she visits and most of times she finds that the available maps are inadequate for her to navigate. Her cognitive cues are developed based on landmarks she identifies and thus she forms her own illustrations.

During the voyage when Michael's co-traveler Asuntha's story unveils she is found alone in her hut in the light of the barely lit lamp searching for her mother. Each night she stayed in her hut waiting for her mother's return, she drew maps of the countryside planning to search for her mother. She traces the rivers, trees and abandoned places where she could possibly find her mother.

Emily, Mynah and Asuntha under the necessity to understand spaces rely highly on the construction of cognitive maps. They comprehend spatial relations gained through both primary experience and secondary media and process the spatial information by forming illustrations sometimes in their mind and at necessary stages transform the information into first hand evidences. According to the complexity of the situation, the processing of the maps also becomes complex.

The Cat's Table tells the tale of human struggle of mapping a place that one can cognominate himself to. Though a story of dislocation, displacement and diasporic experience, it still features space and its categorical peculiarities. The characters in the novel are all in a process of being transplanted from their homelands to spaces where they struggle to mark their existence. In this complexity of tussle between existence and living, cognitive maps not only enhance their memory of the homeland but also aids in a better perception of the new land.

\section{Conclusion}

Human memory is as perplexing as the sketch of a landscape carved by the complexities of the past. An aggregate number of external factors can stimulate the process of memory encoding as well as retrieval and affinity towards landscape is one such factor. Land resides in its indweller and human beings carry their 'self' in all the spaces they travail. Thus, the inherited spaces define and designate an individual better than an autobiography. Individuals continuously yearn for the emotions instigated by a place and it can anchor memories and define identity, behavior, and perceptions. They embody history and memory, and the past lost identities are replenished in the tranquility of inherent spaces.

Cognitive maps are "figures of memory" representing the external environment, and elements in the environment. They are self-organizing systems extending beyond an individual's mind to the external environment. The socio - mental topography of the past is registered and 
organized in human minds typically with a cognitive focus through cognitive maps. These structural positioning of mental imageries representing the external world assists human extensional reasoning, memory encoding and retrieval. Spatial information is transferred into cognitive representations and this enumerates spatial behavior, navigation through complex spaces and memory of spaces.

In Michael Ondaatje's Warlight, memory is conscientiously created and recreated so as to reveal devastating and irresolute truths to the characters in the novel, where they build the meaning of their past experiences. Nathaniel's thirst to discover his past is harboured by spaces which he and his family once ingrained. Nathaniel recollects his parents' avocations during the war in the tranquility and assurance of his childhood home which triggers his memory about his early life without parental supervision, under the custody of The Moth. He organizes his memory combining recollection, history and imagination and discovers his lost inheritance. Rose, Nathaniel's mother though separated herself from her parents and children displays a strange affinity towards spaces. The characters in the novel utilize cognitive maps as a tool to encode and retrieve spatial information. Rose and Marsh Felon use their ability to cartographically depict long-range terrains to serve as spies during and after the war. Nathaniel perceived spatial information and transferred it into maps that exactly radiated his environment. His maps were manifestations of his insecurity.

In the second novel, The Cat's Table by Ondaatje portrays a spectacular sea voyage through its recollection after many years. This voyage furnishes their identities and years later in Michael's recollection of it, his present identity is recreated. The protagonist Michael has an unstable childhood with fragmented life experiences, but he was Colombo, Oronsay -the ship and the ocean. Michael is being transplanted from his homeland to spaces where he struggles to mark his existence. The ties created during dislocation are contrasted with the longing for home and this attachment to home and then to the ocean assists in his recollection. The unique convalesce of past, present and future is attained through making sense of spaces he belonged to in the past. The Cat's Table depicts the struggle of mapping a place and navigating in it. The space and its categorical features are comprehended by the boys in the ship through cognitive maps. Michael withstands the trauma of spacelessness and conflicting attributes of Colombo, Oronsay and London through effective spatial analysis facilitated by cognitive maps. Characters like Emily, Ramadhin and cassius are depending on the construction of cognitive maps for navigating in the new spaces and also to perceive their sea voyage. Cognitive maps not only embellish their memory of the homeland but also facilitate an improved conception of the new land.

"'place' places man in such a way that it reveals the external bonds of his existence and at the same time the depths of his freedom and reality" (Heidegger 1958). How memory and geography form human beings in their ongoing process of 'becoming' is still a matter of mystery. Memories play a pivotal role in the geographic enterprise of 'becoming identities in places'. Places are always being established and reestablished in a complex interplay of the remembered and forgotten, settled and the unsettled and past and the novel events of present. Thus, interrelation between place and human memory remains analogous.

\section{References}

Ondaatje, M. (2012). The cat's table. New York: Vintage International.

Ondaatje, M. (2019). Warlight. New York: Vintage International. 
Bhabha, H. (1995). Cultural diversity and cultural differences. New York: Routledge.

Clifford, Geertz.(1973). The Interpretation of Cultures. Basic Book, Inc, Publishers.

Cosgrove, D. and Jackson, P. (1987). New directions in cultural geography, Area.

Heidegger, Martin. (1958). The Question of Being. London: Vision.

Low, Setha M., and Irwin Altman. (1992). Place Attachment. US: Springer.

Nicholls, Peter. (1996). The Belated Postmodern: History, Phantoms and Toni Morrison Psychoanalytic Criticism: A Reader. Cambridge.

Ondaatje, Michael(2010). Running in the Family. Bloomsbury Publishing.

Riley, Robert B .(1979). Reflections on the Landscapes of Memory. Springer.

Stegner, Wallace.(2013). Wolf Willow. Penguin.

Tuan, Yi-Fu. (2013). Landscapes of Fear. Minneapolis: U of Minnesota.

Van Gennep, Arnold, and Caffee, Gabrielle L. (2011). The Rites of Passage. United States: University of Chicago Press.

Ms. Justy Joseph is a doctoral research scholar at the Digital Humanities and Publishing Studies Research Group, School of Humanities and Social Sciences, Indian Institute of Technology, Indore. Her area of specialization is Digital Humanities, Partition literature and Cognitive theory and has done her Master of Philosophy in select Canadian literature exploring memory and Genesis of a present integrity and regenesis of the past, considering the theories of cognitive geography and cognitive bias.

Dr.Nirmala Menon leads the Digital Humanities and Publishing Research Group at the Indian Institute of Technology (IIT), Indore, India. She is an Associate Professor and Head of the School of Humanities and Social Sciences (HSS), Discipline of English, IIT Indore. She is the author of Migrant Identities of Creole Cosmopolitans: Transcultural Narratives of Contemporary Postcoloniality (Peter Lang Publishing, Germany, 2014) and Remapping the Postcolonial Canon: Remap, Reimagine, Retranslate (Palgrave Macmillan, UK 2017). She has published in numerous international journals and speaks, writes and publishes about postcolonial studies, digital humanities and scholarly publishing. 